\title{
Condition of Local Cattle at Slaughterhouses in Phnom Penh City, Cambodia
}

\author{
Theng Kouch ${ }^{1}$, Pen Miranda ${ }^{2}$, Sar Chetra ${ }^{3}$, Kang Kroesna ${ }^{1}$ and Seng Mom $^{4}$ \\ 1. Faculty of Veterinary Medicine, Royal University of Agriculture, Phnom Penh 12400, Cambodia \\ 2. Centre for Livestock Development Studies, Royal University of Agriculture, Phnom Penh 12400, Cambodia \\ 3. Ministry of Agriculture Forestry and Fisheries, Phnom Penh 12300, Cambodia \\ 4. Royal University of Agriculture, Phnom Penh 12400, Cambodia
}

\begin{abstract}
The survey was conducted four times between September 2015 and June 2016 with an interval of three months. Each survey lasted for 7 days at two main slaughterhouses in Phnom Penh city: Chroy Chongva and Beung Salang slaughterhouses. The objective of this study is to evaluate the perceptions of cattle traders on their business and the BCS (Body Condition Score) of cattle arriving slaughterhouses. Results have shown that the interviewed traders started their business between 1995 and 2013 . Most of them bought 3 to 4 cattle per time and slaughtered one head of cattle each day with an interval of one day transit. The buying of cattle relied on collectors and during of the time of study cattle were purcahsed from 13 different provinces. The supply of cattle was high from July to August and low from March to April. When arriving gathering areas nearby slaughterhouse, cattle were sent to slaughterhouse within one day and could be maintained with one week. Beef was mostly sold by themselves and to their relatives for retailing. They also sold beef to outside retailer, distributor and sold at market. The price of beef was high from March to April. High percentage of male cattle were found in slaughterhouses than female cattle with the age of 3 to 6 years old. High distribution of cattle were found to have BCS between 2 and 3 scores, and it is found that male cattle had higher BCS than female cattle. The amount of meat varies with BCS, e.g. up to $57.56 \%$ of total liveweight when BCS was 4 scores. The price of live cattle varies with cattle BCS and meat proportion of animal.
\end{abstract}

Key words: Trader, collector, BCS, period, gender of cattle, price.

\section{Introduction}

In order to ensure long-term food security, particularly for vulnerable groups in the developing world, development finance and policies must favor small farmers who give proper care to their animals, act in accordance with the basic ethic of compassion towards animals under their control, and practice and promote more humane and environmentally sustainable agriculture [1]. However, in Cambodia, the cattle's market is the main constrain for smallholder farmers who own cattle, due to limited access to domestic and export markets, which are increasingly demanding high and consistent quantity and quality beef (Project overview AH/2010/046).

Corresponding author: Theng Kouch, $\mathrm{PhD}$ candidate, research field: ruminant nutrition.
Regarding market problem, the limitation of knowledge and the social behavior prevented the rural farmers who own cattle to get low benefit from selling cattle because they sell cattle whenever they need, even skinny. According a researcher [2] showed that the Cambodian Strategy for Livestock Production (2011) seeks to improve market participation as well as reducing risks of disease. FAO [3] reported that livestock have an important part to play, as they provide high-quality protein to consumers and regular income to producers; and make a vital contribution as generators of cash flow and economic buffers, provided that market chains are organized to provide openings for small scale producers and traders and those in remote areas, thus making production of poultry and bovine meat expanded while pig meat and sheep meat production declined [4]. While the demand 
of meat is the primary driver for a livestock revolution, in developing countries, poor people are consuming more animal products due to their increased income and urbanization [5]. In Cambodia, the official slaughter number of cattle reached a peak at 115,973 head in 2011, and then dropped to 108,272 head in 2013 [6], with the average per capita consumption of meat estimated to be $16.5 \mathrm{~kg}$, beef consumption (5 kg) second range from pork $(9.29 \mathrm{~kg})$, poultry meat (1.84 $\mathrm{kg}$ ), while goat meat is $0.01 \mathrm{~kg}$ only. However, beef consumption in Cambodia is higher than in Thailand (4.39 kg) and Vietnam (3.70 kg), but lower than Malaysia (5.96 kg) [7].

The risk of contaminated meat with concerning public health could result from the abattoir sector has been neglected in most national livestock development programmes throughout Asia and the Pacific, considerable consumers' concern for the improved safety of meat is driving the pressure on governments to initiate substantial hygienic improvements [8]. In Cambodia, the high level of meat contamination came from the poor sanitary conditions in slaughterhouses and meat retailers, while the methods of handling and slaughtering followed traditional ways [9]. However, at the farmer level, the BCS (Body Condition Score) of cattle seems to be low, from 2 to 2.21 for female and male respectively [10], which could affect the cattle quality when supplying to slaughterhouse.

The research is to determine and compare the BCS and price of cattle arriving slaughterhouse with different period, and common practices and perception of trader.

\section{Methodology}

\subsection{Period}

The survey was conducted four times starting from September 2015 to June 2016 every 3 months interval. The survey of each time lasted 7 days.

\subsection{Location}

The data collection was undertaken in two main slaughterhouses located in Phnom Penh city, namely
Chroy Chongva and Boeng Salang Slaughterhouse. The transit areas of cattle nearby the two slaughterhouses were identified. The traders were approached and interviewed wherever possible before they sent their cattle to slaughterhouse or they kept for a period of time there.

\subsection{Data Collection}

The traders were asked with a series of questions using structured questionnaires. The questions focus on their cattle sources, the process of storing their cattle before slaughtering, and their perceptions on beef demand, supply and price. The information on every cattle purchased by traders was recorded using a formal form. Age, gender, BCS, price, amount of meat, bone, internal organs were collected individually.

The cattle BCS was scored which five levels, starting from score number 1 (the thinnest) to score number 5 (the fattest) [11]. All cattle were weighted with electronic scale individually or predicted by the traders; and we recorded the total carcass, bone and internal organs.

\subsection{Data Management and Data Analysis}

The collected data were edited to detect the errors and omission and each questionnaire has been coded for facilitating the analyzing process, then were entered in excel. Excel or SPSS program has been used for data analysis.

\section{Result and Discussion}

\subsection{General Information}

Fig. 1 shows that all 35 traders/slaughterers who were interviewed, started their business with different years between 1995 and 2013. Half of traders started their cattle business after 2006.

The interval of buying and slaughtering cattle was varied from 1 to 5 days, however the frequency of buying and slaughtering in 1 day interval occupied high percentage, $60.87 \%$ and $72.68 \%$ respectively (Fig. 2). 


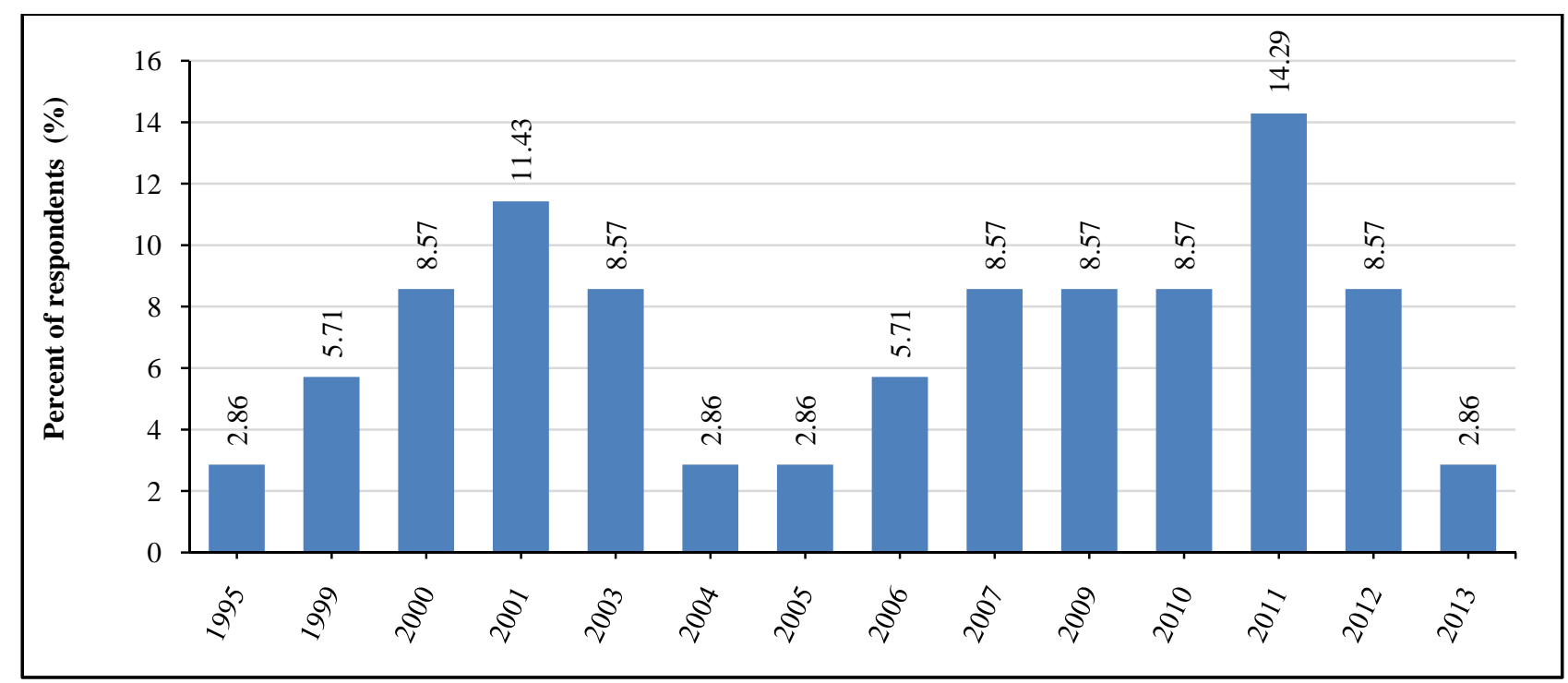

Fig. 1 The year of starting cattle business by 35 respondents.

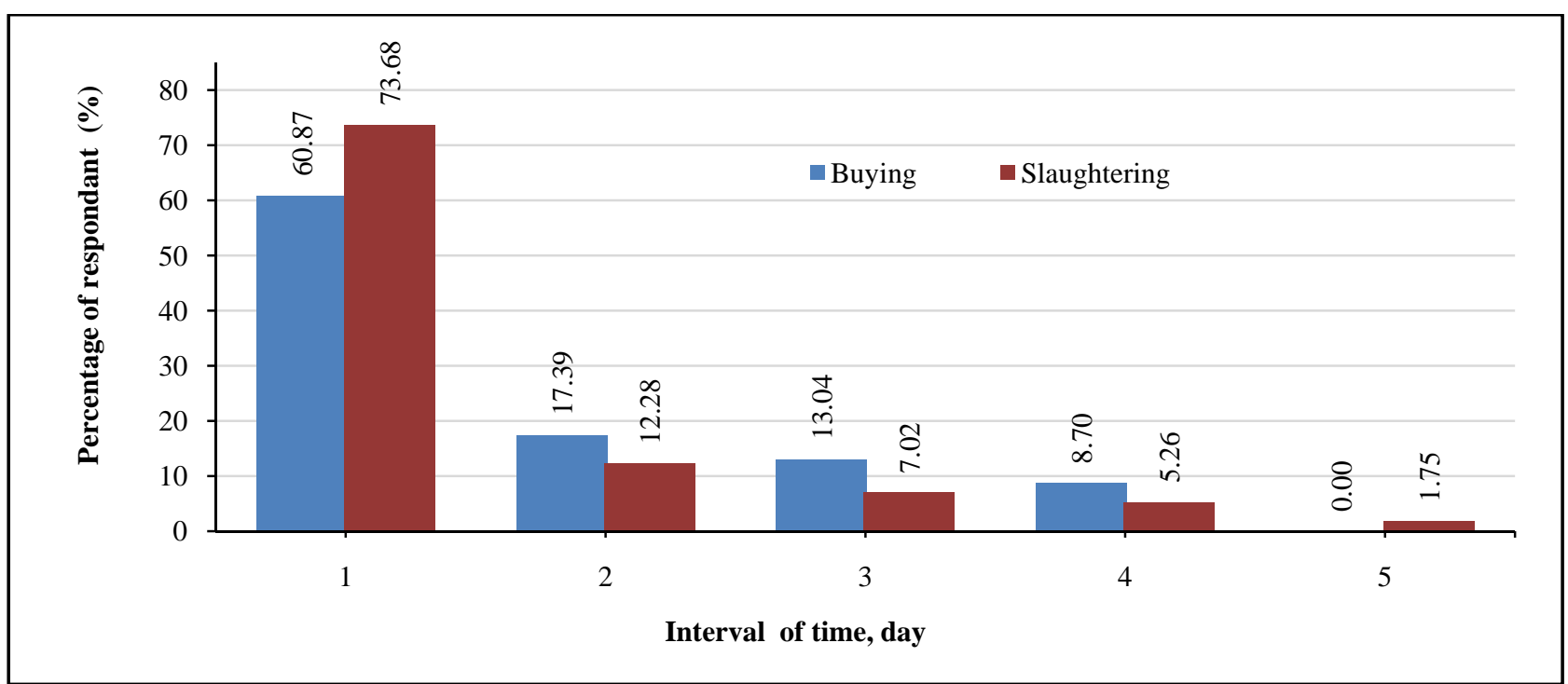

Fig. 2 Time for buying and slaughtering.

The number of cattle bought and slaughered per time varied, for purchasing only purpose ranged from 1 to 40 cattle, while for slaughtering only purpose ranged from 1 to 15 cattle. For purchasing only purpose, number of cattle with 3 and 4 heads per time occupied highest percentage of $19 \%$ and $14 \%$ respectively, while for slaughtering only purpose of cattle per time was 1 head occupied highest percentage (24.56\%) (Fig. 3).

The modes of purchasing cattle were varied. The traders relied mainly on collectors (62.07\%), on famers (20.69\%) and on both famers and collectors (15.52\%). It is a very rare case that traders directly bought the cattle from farmer (Fig. 4).

The cattle arriving slaughterhouses during the study originated from 13 different places listing 12 provinces and one city (Fig. 5). Most of respondents (64.41\%) purchased cattle from Kampong Thom, Preah Vihear (62.71\%) and Siem Reap (59.32\%) provinces. Two provinces are located along the Tonle Sap lake, known as the main water reservoir and those above three provinces shared the provincial border together (Fig. 5). 


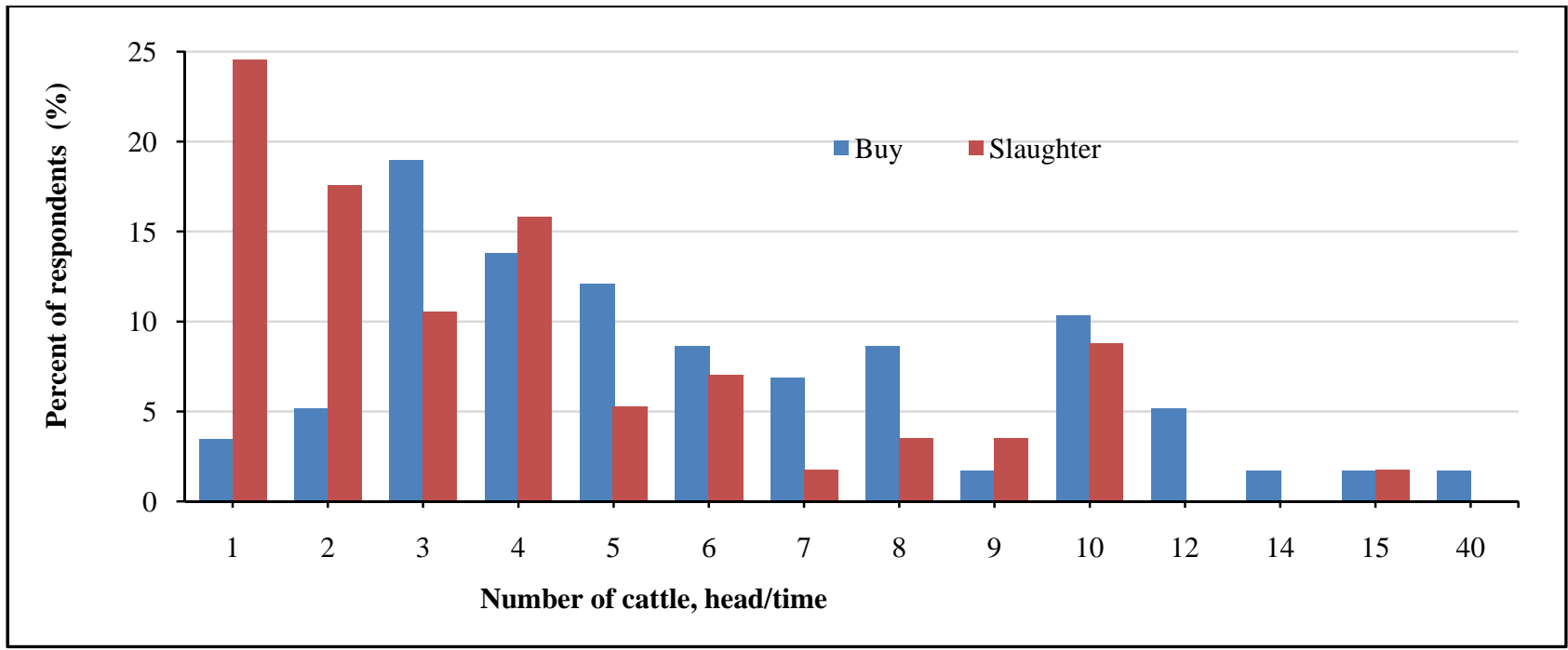

Fig. 3 Numbers of cattle purchased and slaughtered per time.

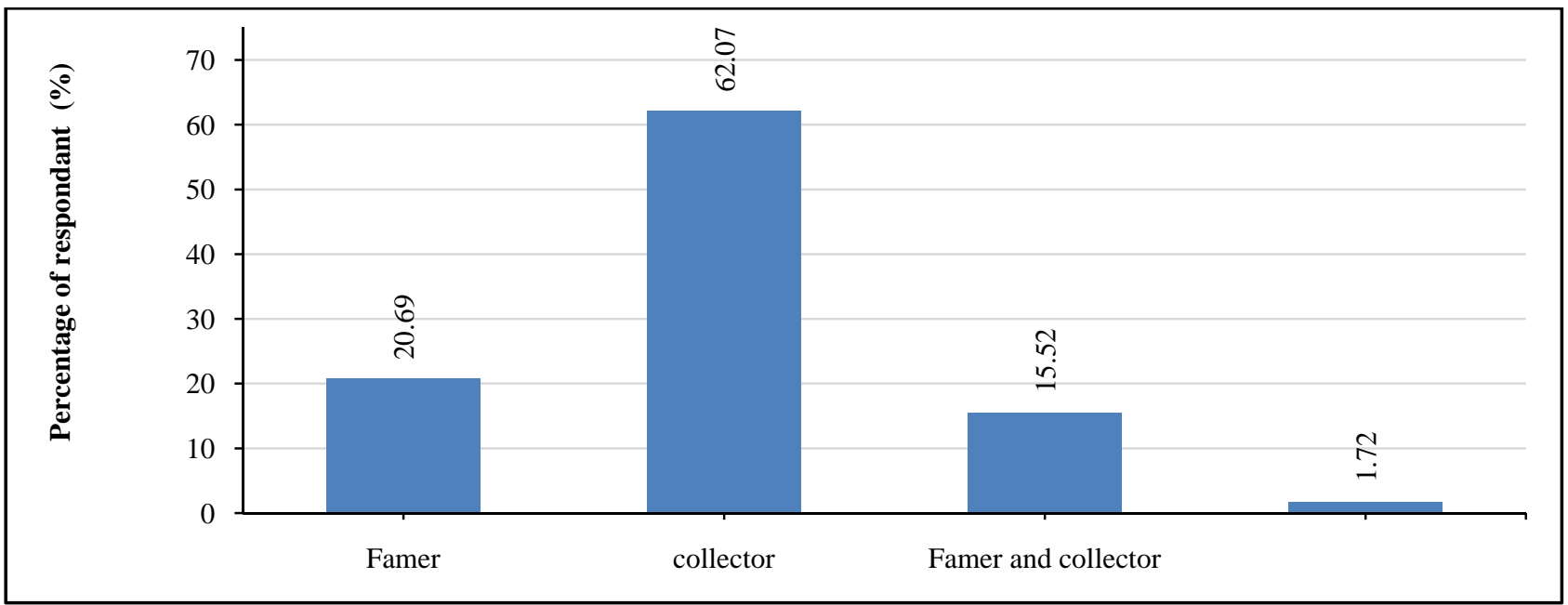

Fig. 4 Method of purcahsing.

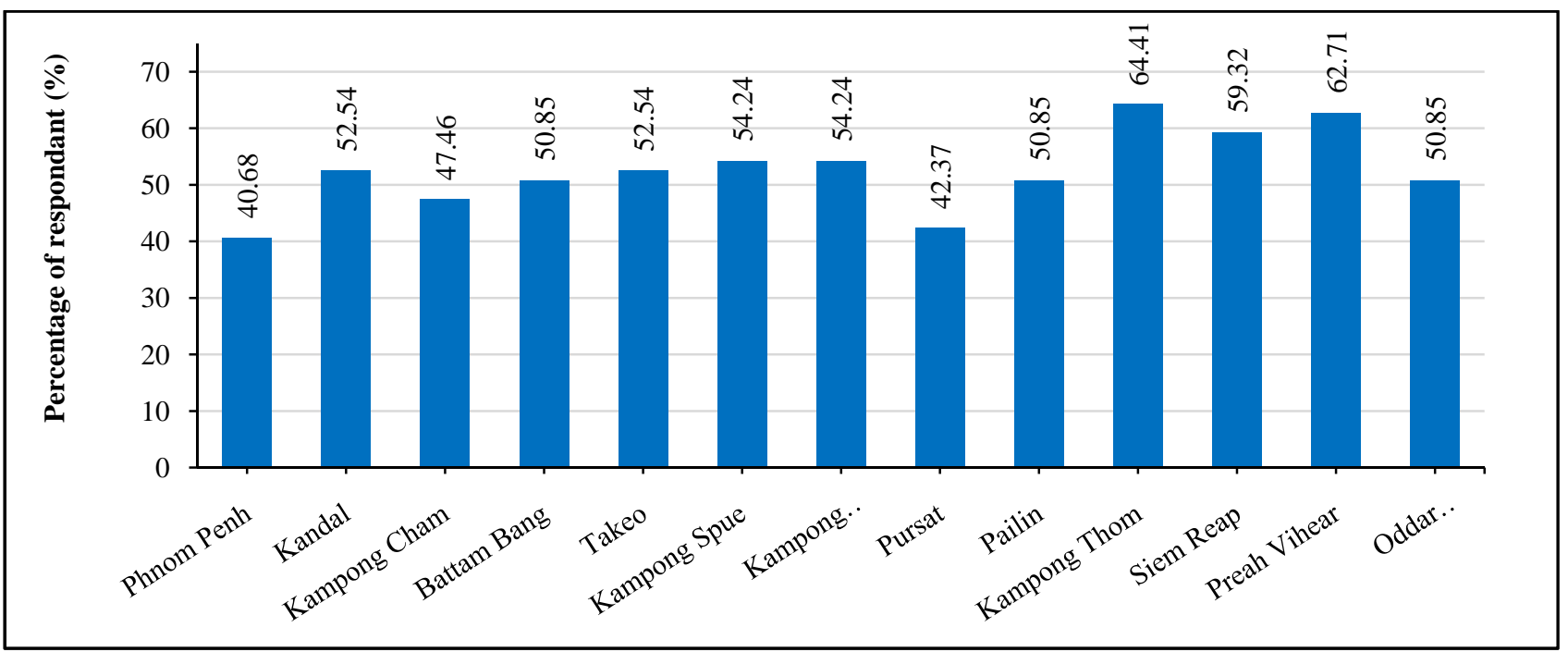

Fig. 5 Sources of cattle by province. 


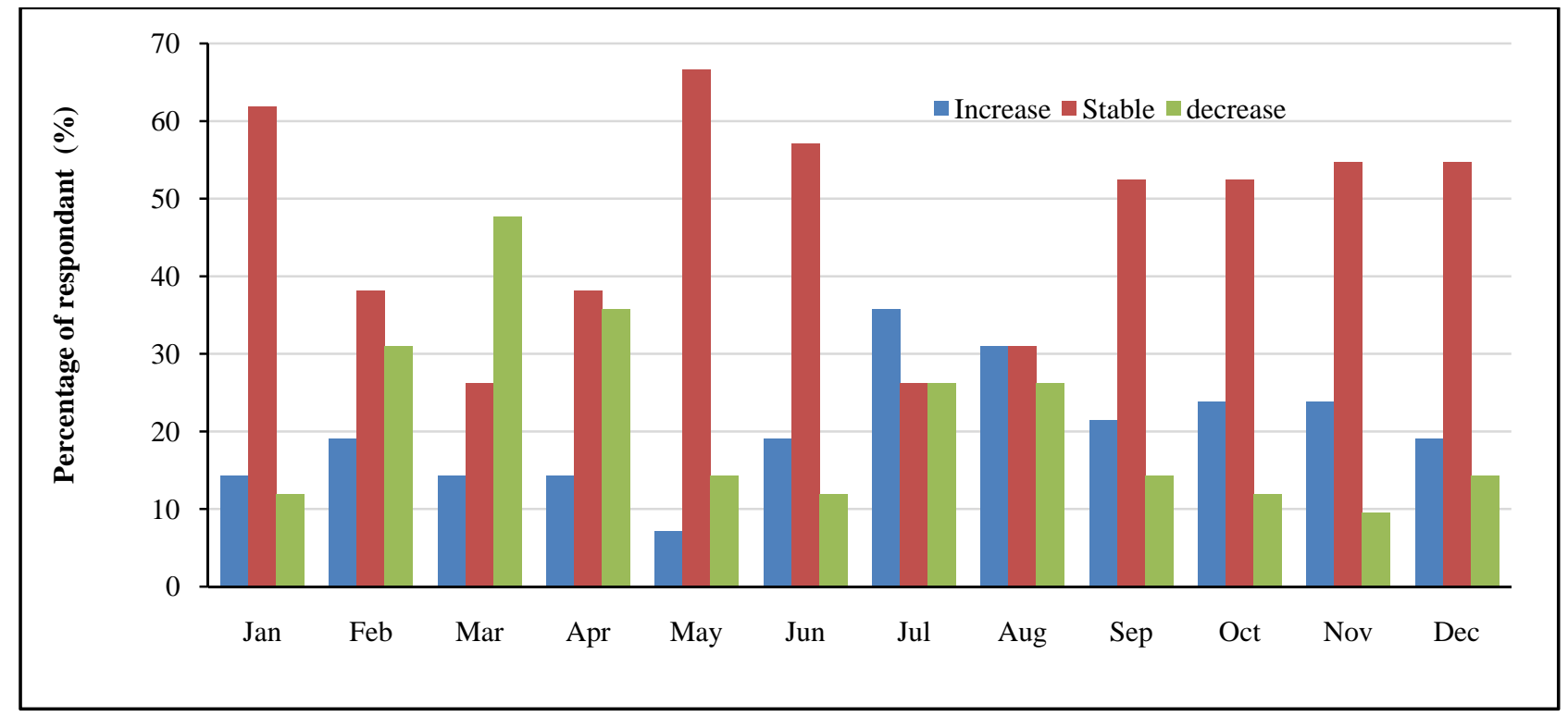

Fig. 6 The perspective of traders on cattle supply within the year of study.

Table 1 Types of handling of cattle after the collection.

\begin{tabular}{llll}
\hline \multirow{2}{*}{ No. } & Types of handling & \multicolumn{2}{c}{ Parameters } \\
\cline { 3 - 4 } & Slaughterhouse & 13 & Percentage (\%) \\
\hline 1 & Store for short time & 2 & 34.21 \\
3 & Fattening & 4 & 5.26 \\
4 & Slaughterhouse and store in short time & 16 & 10.53 \\
5 & Slaughterhouse and fattened & 1 & 42.11 \\
6 & Slaughterhouse, store and fattened & 2 & 2.63 \\
\hline
\end{tabular}

Table 2 Mode of selling of beef after slaughtering.

\begin{tabular}{llll}
\hline \multirow{2}{*}{ No. } & Type of selling & \multicolumn{2}{c}{ Frequency } \\
\cline { 3 - 4 } & & Person & Percentage (\%) \\
\hline 1 & Sold by traders and to relatives & 14 & 33.33 \\
3 & Distributor & 9 & 21.43 \\
4 & Seller at market & 3 & 7.14 \\
5 & Whole seller & 7 & 16.67 \\
6 & $1 \& 3$ & 3 & 7.14 \\
7 & $1 \& 4$ & 3 & 7.14 \\
\hline
\end{tabular}

The perception of cattle supply of traders have shown that from July to August there was a highest supply of cattle than other periods, while between March and April there was a lowest supply within the year (Fig. 6).

The traders chose to either send their cattle to slaughterhouses immediately or keep for a short period of time (42.11\% of respondents). One third of respondents slaughtered their cattle immediately at the slaughterhouse. Very few traders kept their cattle for fattening and finishing period before sending to slaughterhouses (Table 1).

For mode of selling beef, 33.33\% of respodents chose to sell the beef by themselves at the market or to their relatives, then $21.43 \%$ sell to distributor, and whold seller (16.67\%), however, there were no answers about $7.14 \%$ (Table 2). 
The price of beef varied based on seasonal basis within the year of study. According to the perspectives of traders, it increased between March and April and decreased during July, August and September (Fig. 7).

Looking at the demand of beef, it is found to be reasonable to explain the price of beef above, the demand of beef increased in March and April, but it decreased in July, August and September (Fig. 8).

\subsection{The Characteristics of Cattle Arriving Stocking} Areas and the Slaughterhouses

During the period of the four surveys at different times of the year (September, December, March and June), 877 cattle at Chroy Chongva and Boeung Salang slaugtherhouses and nearby stocking areas were selected to study on their characteristics (Table 3).

The result in Fig. 9 showed that there was different significance among the numbers of cattle at slaughterhouse with gender $(p<0.001)$. Cattle arriving the slaughterhouses or nearby stocking areas were majority of male cattle (83.50\%) and only $16.5 \%$ were female cattle.

The distribution of age of cattle arriving slaughterhouses was mostly between 3 and 7 years old.

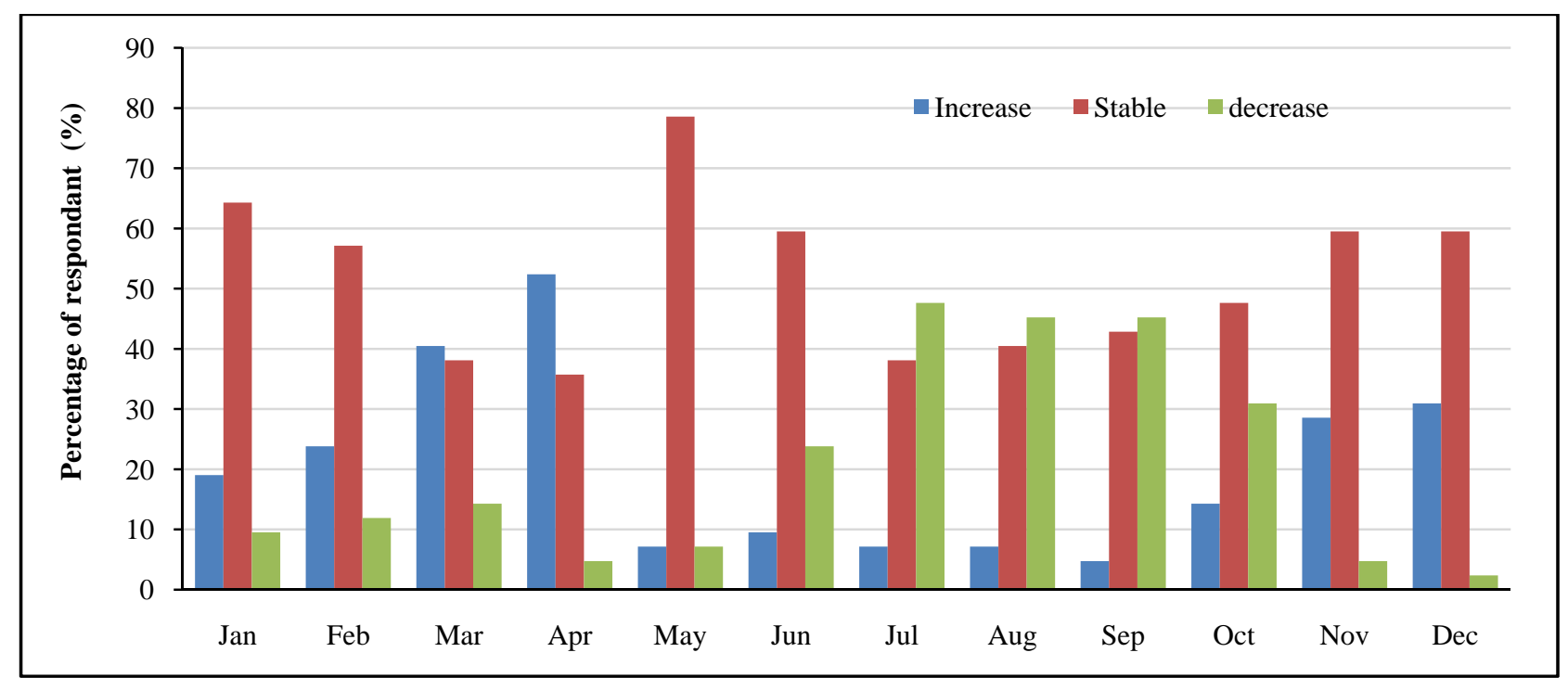

Fig. 7 The perspective of traders on cattle price within the year of study.

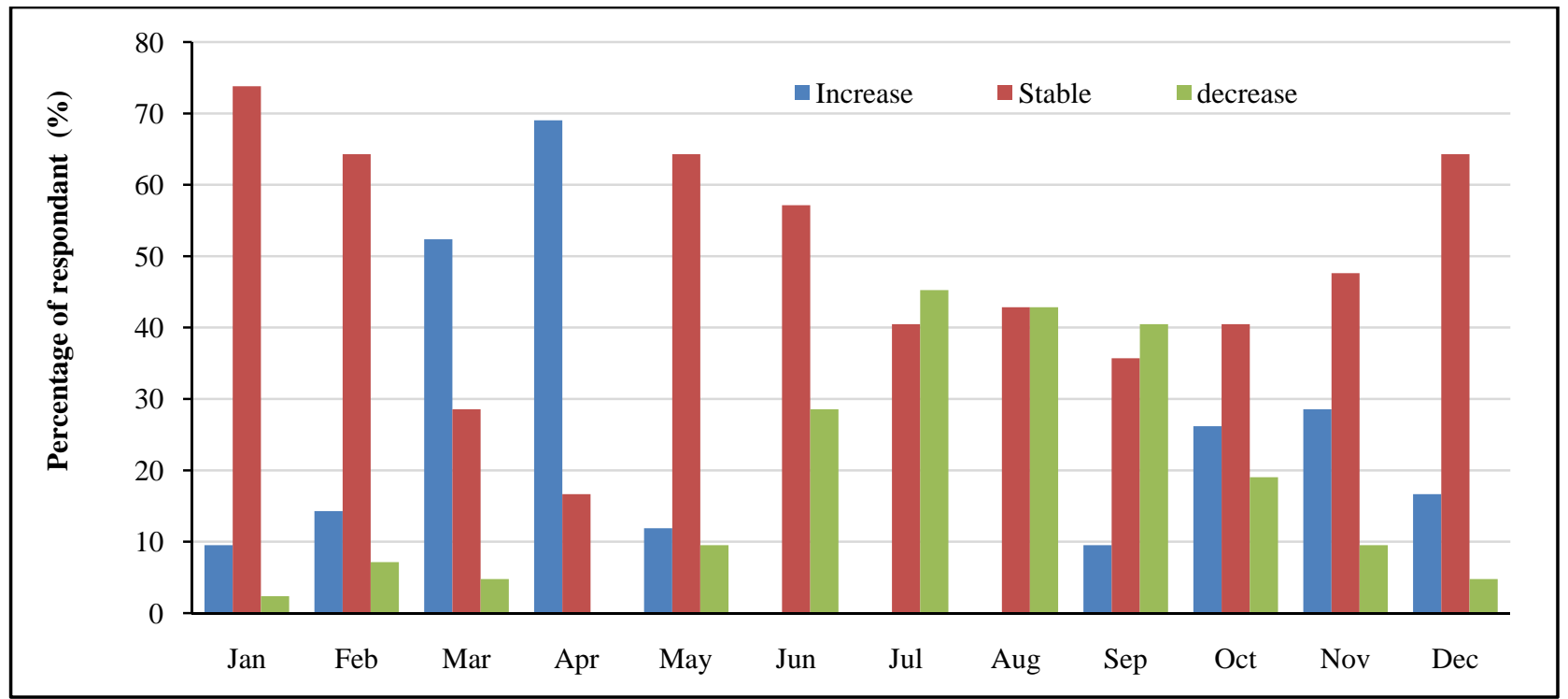

Fig. 8 The perspective of traders on demand of beef within the year of study. 
Table 3 Number of sampling cattle at Chroy Chongva and Boeung Salang slaughterhouses and nearby stocking areas.

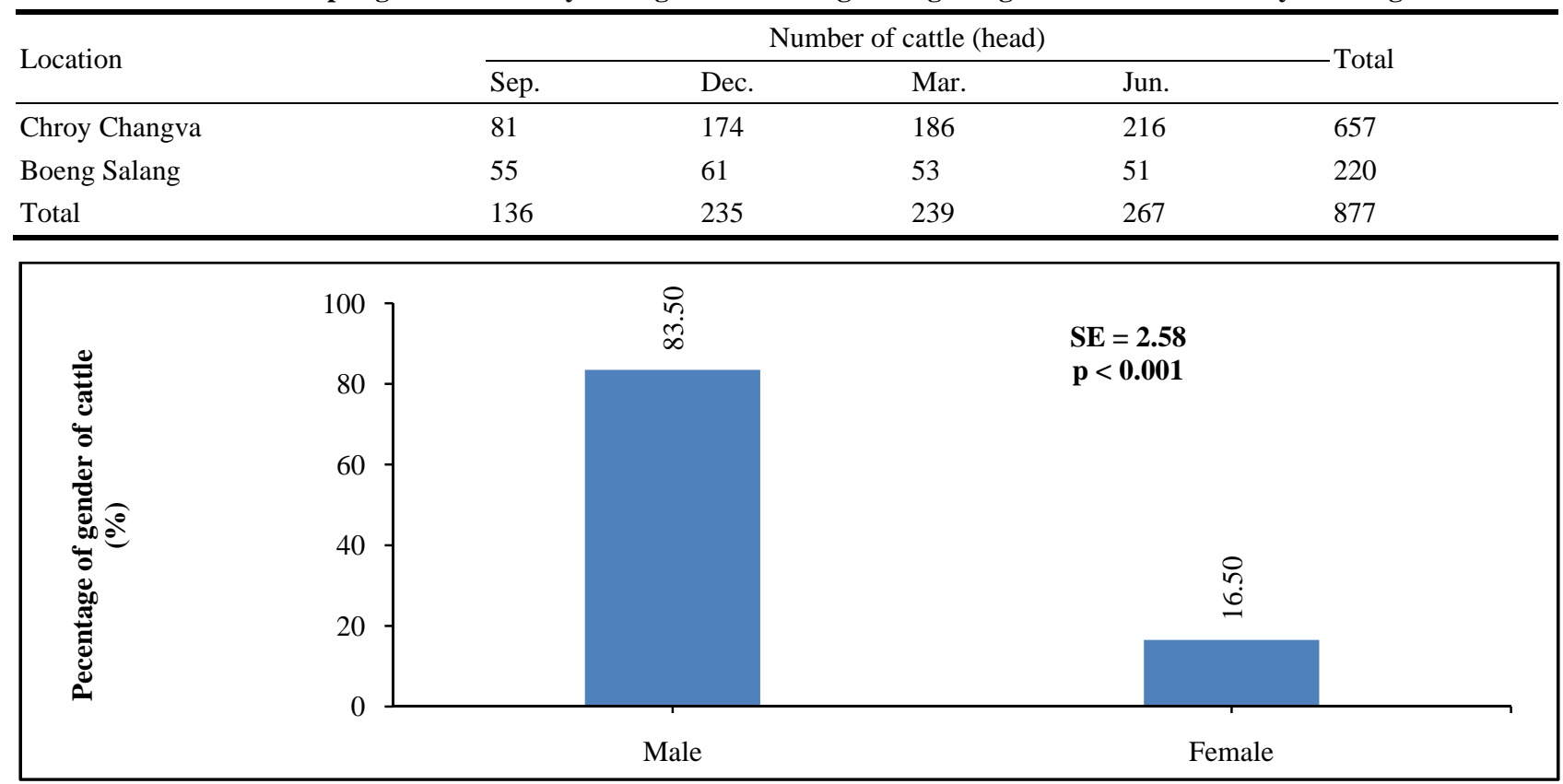

Fig. 9 Percentage of cattle arriving slaughterhouses by gender.

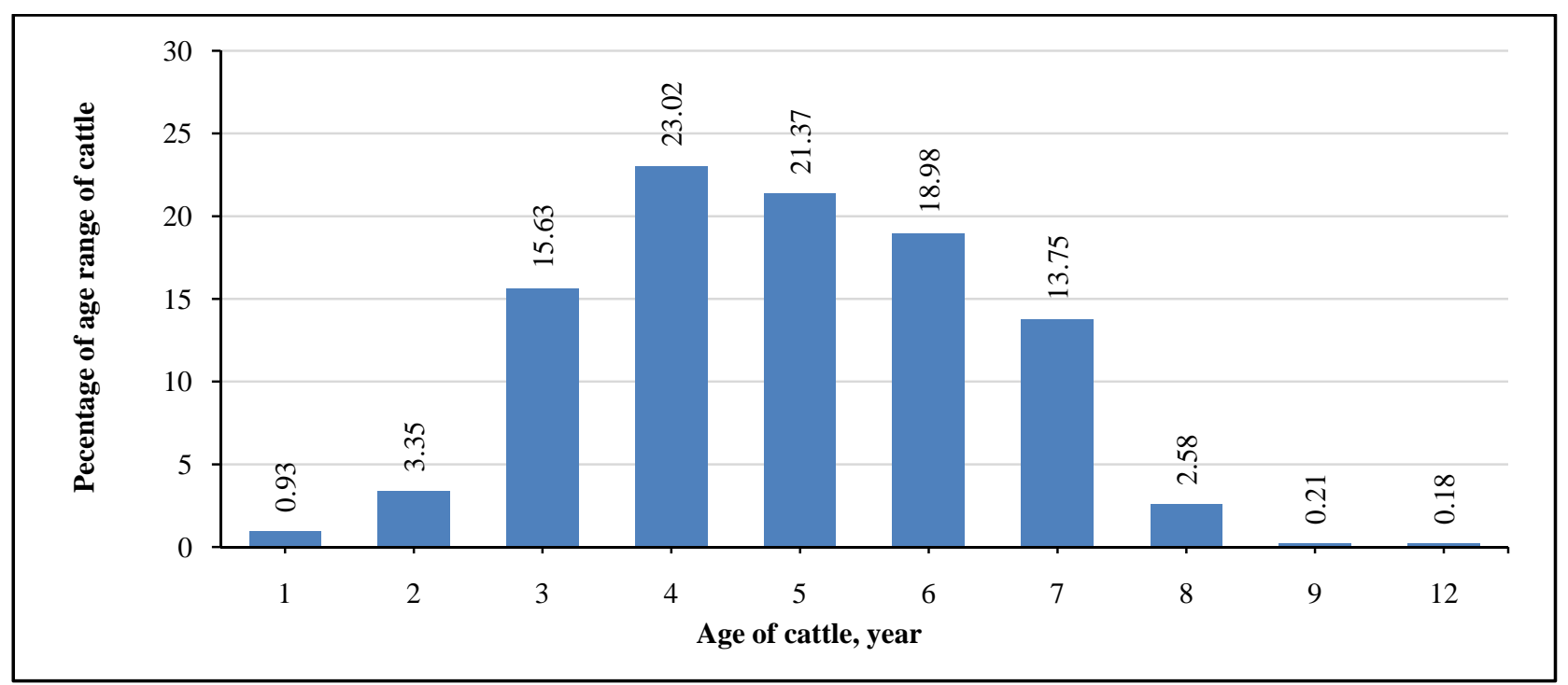

Fig. 10 Percentage of cattle arriving the slaughterhouses by age.

The percentages of cattle were the following: 3-4 years old (23.02\%), 4-5 years old (21.37\%), 5-6 years old (18.98\%). Percentages of young and very old cattle arriving the slaughterhouses were very low, e.g. age of $\leq 1$ year old, 1-2 years old age or 8-12 years old (Fig. 10).

When the cattle are structured by age of different gender, the distribution of male and female cattle was similar even though there are some differences. The highest percentage is $26.48 \%$ for female cattle at age of $4-5$ years old and $23.93 \%$ for male cattle at similar age (Fig. 11).

There was slight difference in percentage of cattle BCS at different time of the year. Overall, cattle arriving the slaughterhouses had BCS of 2 and 3 (48.72\% and 43.21\% respectively). In period between September more cattle had BCS of 2 and 3 and slight increase in percentage of cattle with BCS of 4 in 


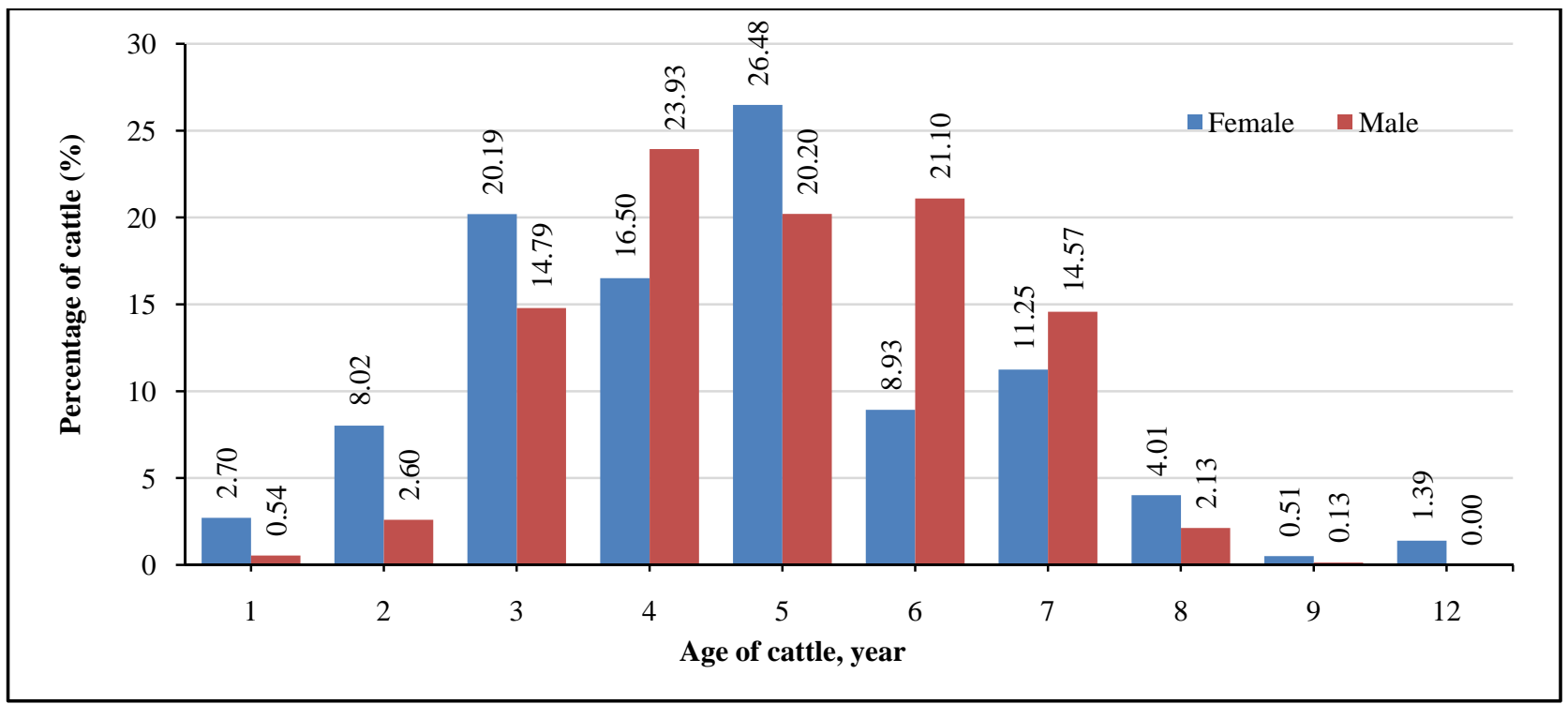

Fig. 11 The distribution of cattle arriving the slaughterhouses by age and gender.

Table 4 Percentage of cattle by BCS1 to BCS4 and by different times of survey.

\begin{tabular}{llllll}
\hline BCS & Sep. (\%) & Dec. (\%) & Mar. (\%) & June (\%) & Average (\%) \\
\hline BCS1 & 2.21 & 1.28 & 2.51 & 3.00 & 2.25 \\
BCS2 & 44.12 & 45.11 & 50.21 & 55.43 & 48.72 \\
BCS3 & 47.06 & 40.85 & 45.61 & 39.33 & 43.21 \\
BCS4 & 6.62 & 12.77 & 1.67 & 2.25 & 5.83 \\
SE mean & - & - & - & - & 2.06 \\
$p$ value & - & - & - & - & $<0.001$ \\
\hline
\end{tabular}

Table 5 Average BCS of cattle by gender at different time of the year.

\begin{tabular}{llllll}
\hline Gender of cattle & Sep. & Dec. & Mar. & Jun. & Mean \\
\hline Male & 2.39 & 2.51 & 2.32 & 2.36 & 2.40 \\
Female & 2.03 & 2.08 & 2.00 & 1.95 & 2.02 \\
SE & - & - & - & - & 0.035 \\
$p$ value & 0.017 & 0.001 & $<0.001$ & $<0.001$ & $<0.001$ \\
\hline
\end{tabular}

December period. And increasing percentage of cattle with lower BCS are found during dry season (March) and early rainy season (June) (Table 4).

However, the BCS distribution by gender of cattle shown that there was different significance between male and female cattle $(p<0.001)$, the male cattle had higher BCS than female cattle with the average 2.40 and 2.02 respectively (Table 5).

The percentage of meat has varied with BCS, the high BCS had the high percentage of meat they got, thus BCS at level 4 had high percentage of meat, $57.56 \%$ of bodyweight (Fig. 12).

In general, the frequency of body weight of cattle at slaughterhouse was higher for weight from 100-250 $\mathrm{kg}$ (from 22.30\%-25.57\%), while the lower weigh ( $\leq$ $100 \mathrm{~kg}$ ) or we call young/small cattle had low percentage (3.42\% only) (Fig. 13).

The price of cattle depends on the live weigth of cattle, normally the traders esptimated the body weight before putting the price (Fig. 14). However, the proportion of meat was also carefuly considered befor giving the price, it meant that fat cattle or high BCS cattle will get high price, since these cattle have provided high proportion of meat (Fig. 15). These correlation meant that the more heavy weigh or high proportion meet of cattle had the higher price. 


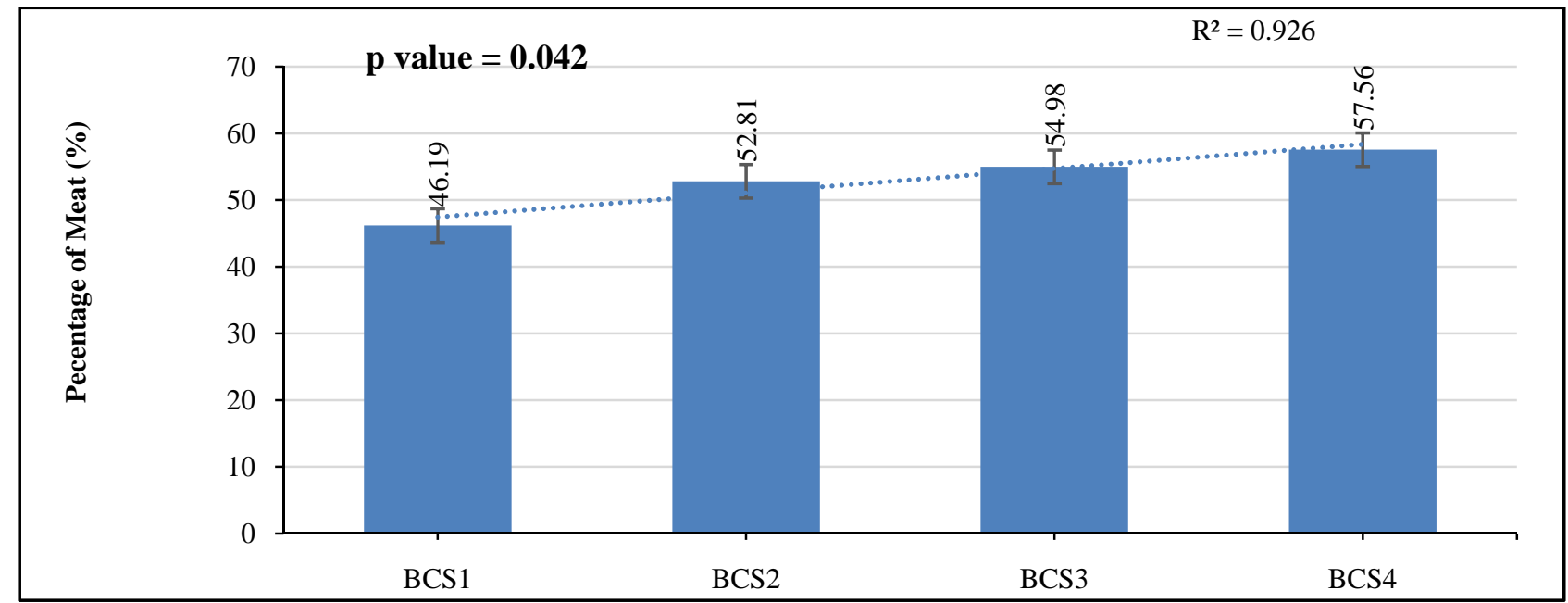

Fig. 12 Percentage of meat with BCS.

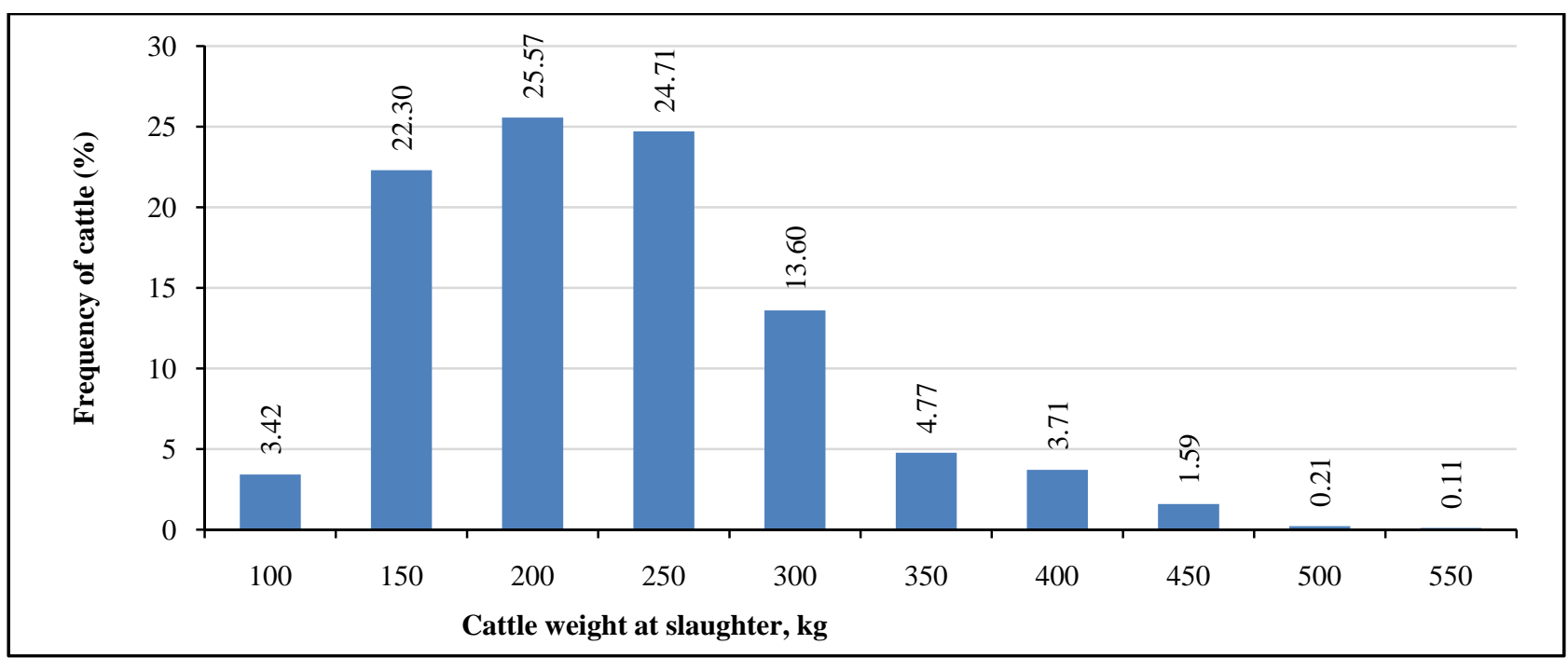

Fig. 13 Distribution of Cattle weight.

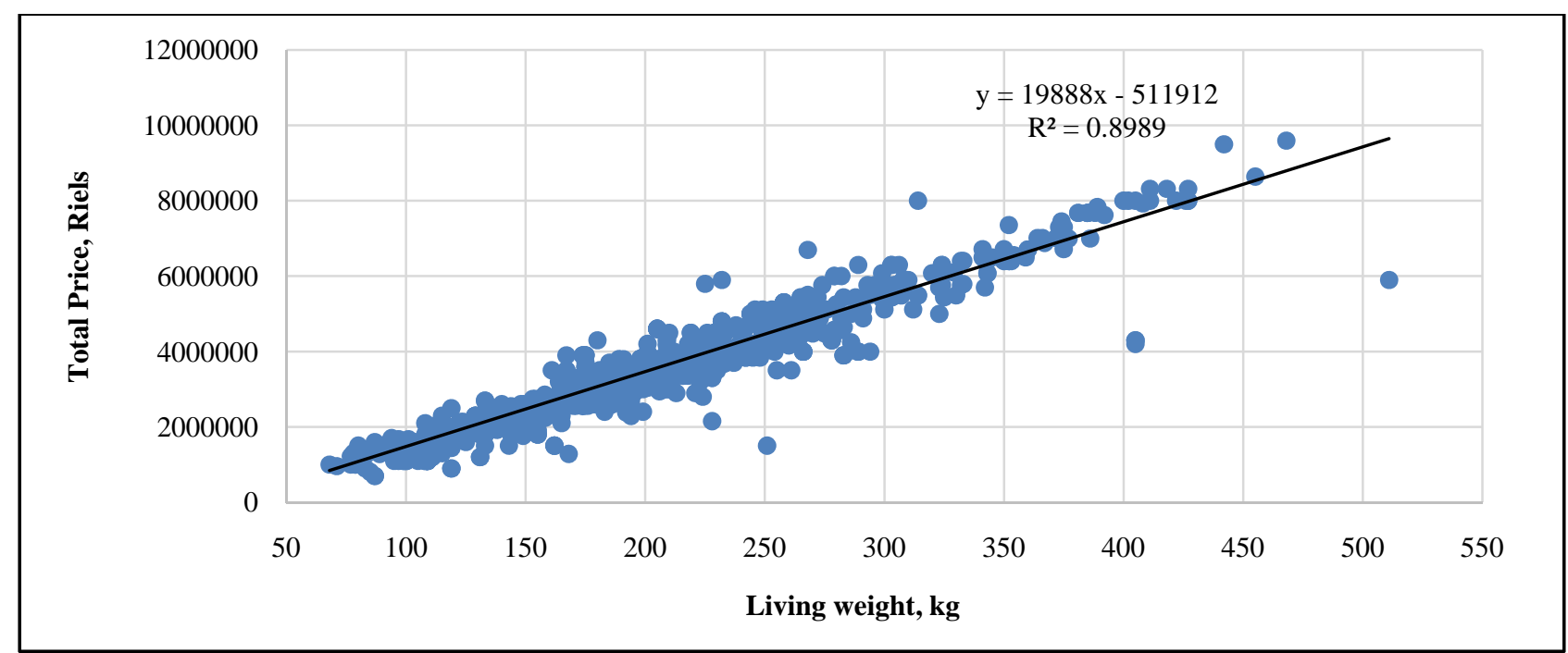

Fig. 14 Correlation of price with living weight. 


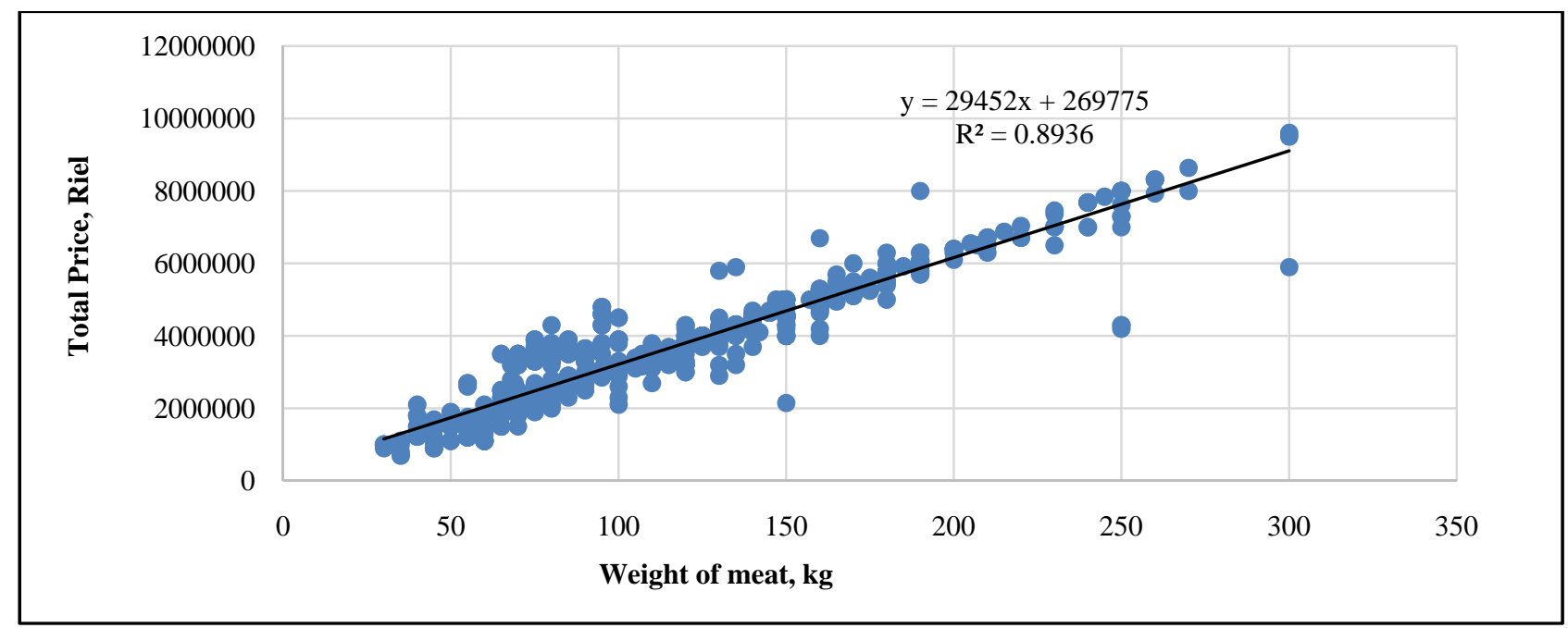

Fig. 15 Correlation of price with weight of meat.

\section{Discussion}

In July and August, there was more supply of cattle than in March and April, this was the reason for the increase in the price of beef in March and April. Another reason that could explain this phenomenon is the low contribution of other meat in the market, especially fishes during dry season. When cattle arrive stocking areas, most of them were sent immediately to slaughterhouses or were stored for a short period of time. After the cattle were slaughtered, the beef was mostly sold by traders themselves and to relative for retail to end-consumers.

The gender distribution of cattle at slaughtering was male cattle with higher percentage than female cattle, and the age 3-6 years old was higher than other age. For the BCS of cattle with \#2 and \#3, male cattle had higher BCS than female cattle. This result of BCS agreed with the report of finding at the village level by recent study [10].

The meat proportion has varied with BCS and up to $57.56 \%$ when BCS was up to 4 . Thus, the price of live cattle has varied with cattle weight or percentage of meat. The traders estimated the amount of meat on live animal and then give the price by kilogram (kg) of estimated meat. It similar finding of a researchers reported that while animals were not weighed during the purchasing, the price was based on an estimation of meat yield per animal [12]. In general, live weight of cattle at slaughterhouse was high for the 200-250 $\mathrm{kg}$, it was similar with the finding of one researcher [6] that the average weight was $250 \mathrm{~kg}$.

\section{Conclusion}

In summary, most cattle traders prefer to buy cattle on daily basis from collectors, while slaughtering took place every day. The majority of slaughtered cattle were male cattle with an average of BCS of 2 and 3 and slightly varied at different time of the year. The demand, supply and price of beef were different seasonally and strongly correlated.

\section{Acknowledgement}

The author would like to acknowledge the Beef for Market (B4M) project of ACIAR, Australia, managed by Dr. Ian Patric and his colleagues, and the Royal University of Agriculture for financial and technical support for this study.

\section{References}

[1] HIS. 2011. The Impact of Industrial Farm Animal Production on Food Security in the Developing World Report. Human Society International.

[2] Muniroth, S., Patrick, I., and Smith, G. 2010. "Cattle Market Chain in South-East of Cambodia."

[3] FAO. 2011. World Livestock 2011. Livestock in Food Security. Rome: FAO. 
[4] OECD-FAO. 2017. Agricultural Outlook 2017-2026. Paris: OECD Publishing. http://dx.doi.org/10.1787/agr_outlook-2017-en.

[5] Delgado, C. L. 2003. "Rising Consumption of Meat and Milk in Developing Countries Has Created a New Food Revolution.” The Journal of Nut. 133 (11): 3907S-10S.

[6] Luong, P., Smith, D., Soun, S., and Sau, V. 2015. "The Cambodian Beef Industry.” In Regional Workshop on Beef Markets and Trade in Southeast Asian and China, Ben Tre, Vietnam, 30th November-3rd December, 2015.

[7] MAFF. 2014. "Policy Study on Cattle Production Development in Cambodia: Risk and Opportunities for Poor and Landless Households.”

[8] FAO. 2008. "Abattoir Development, Options and Designs for Hygienic Basic and Medium-Sized Abattoirs."

[9] Tum, S. 2008. "Reducing Microbial Contamination of
Meat at Slaughterhouses in Cambodia.” Policy Brief. safetynet2008.com.

[10] Theng, K., Pen, M., Sar, C., Kang, K., and Seng, M. 2019. "Impact of Forage Programme on Cattle Body Condition Score of Smallholder Farmers in Cambodia.” Journal of Environmental Science and Engineering B 8: 93-102.

[11] DEFRA. 2001. Condition Scoring of Beef Suckler Cows and Heifer. DEFRA (Department for Environment, Food and Rural Affaire), PB6491. http://adlib.everysite.co.uk/adlib/defra/content.aspx?doc= 15756\&id=17951.

[12] Pen, M., Savage, D. B., Lorn, S., and Stür, W. 2014. "Beef Market Chain and Opportunities for Farmers in Kampong Cham Province, Cambodia.” International Journal of Environmental and Rural Development 5 (1): 32-7. 